\title{
OS DIREITOS HUMANOS E A POLÍTICA INTERNACIONAL
}

\author{
Rossana Rocha Reis
}

\begin{abstract}
RESUMO
O artigo trata da questão do crescente reconhecimento internacional dos direitos humanos desde o fim da II Guerra Mundial e discute os efeitos desse processo sobre a política internacional. De modo geral os argumentos sobre o papel dos direitos humanos na politica internacional dividem-se entre os que acham que eles não passam de retórica para encobrir interesses particulares, e os que enxergam na sua afirmação um potencial transformador da ordem internacional. No contexto atual,em que se discute a adoção de mecanismos coercitivos mais fortes para a proteção dos direitos humanos, como as intervenções humanitárias, por exemplo, essa discussão torna-se mais complexa e mais urgente.
\end{abstract}

PALAVRAS-CHAVE: direitos humanos; intervenções humanitárias; politica Internacional; ONU.

"Só a história poderá resolver, algum dia, o eterno debate do maquiavelismo e do moralismo" (Raymond Aron).

\section{INTRODUÇÃO}

A idéia de que existe um conjunto de direitos inalienáveis que todo e cada um dos seres humanos possui pelo simples fato de ser humano tem uma longa tradição na história do pensamento. No entanto, é apenas a partir da segunda metade do século XX que o reconhecimento desses direitos passa a ser afirmado internacionalmente pela elaboração de cartas de direitos, tratados e convenções internacionais, e da incorporação da temática dos direitos humanos na elaboração da política externa de diversos estados.

A afirmação de que a "sociedade internacional" tem responsabilidade pela vida e pela proteção dos direitos humanos do indivíduo, independentemente de seu próprio Estado, ganha força após a II Guerra Mundial, especialmente diante da proliferação dos refugiados e apátridas - o que Celso Lafer chama de "os expulsos da trindade povo-Estado-território". A percepção do abandono em que se encontrava o indivíduo quando não estava vinculado a nenhum Estado motivou a criação de um regime internacional que representa um ponto de inflexão no direito internacional, pois pela primeira vez é reconhecida a existência do indivíduo no cenário internacional.
De modo geral, a assinatura da Carta de fundação da Organização das Nações Unidas (ONU) (1945), a carta de fundação do Tribunal de Nuremberg (1945-1946) e a Declaração Universal dos Direitos Humanos (1948) são consideradas os marcos fundadores do direito internacional dos direitos humanos. Em linhas bem gerais, pode-se dizer que a Carta da ONU reconhece como legítima a preocupação internacional com os direitos humanos, o Tribunal de Nuremberg estabelece a responsabilidade individual pela sua proteção e a Declaração enumera o conjunto de direitos civis, políticos, econômicos e sociais, considerados fundamentais, universais e indivisíveis.

As interpretações sobre as razões que levaram originalmente os estados a comprometerem-se internacionalmente com os direitos humanos variam, como era de esperar, entre aqueles que consideram que a Declaração representa um avanço em termos da realização dos ideais mais elevados da humanidade - como, por exemplo, o jurista e cientista político italiano Norberto Bobbio, que considera que a Declaração de 1948 "representa a consciência histórica que a humanidade tem de seus próprios valores fundamentais na segunda metade do século XX" (BOBBIO, 1992, p. 34) - e aqueles que consideram que os estados só aceitaram um 
compromisso em torno do ideário de direitos humanos porque consideravam que ele não teria conseqüências importantes, uma vez que nem a ONU nem qualquer outro tipo de organização internacional eram dotados da capacidade ou da legitimidade necessária para exigir dos estados a observância dos direitos humanos. Ao mesmo tempo, no entanto, a promoção do regime internacional de direitos humanos, ainda que apenas formal, serviria como uma resposta a todos aqueles que, em diversos lugares do mundo, continuavam horrorizados diante das revelações sobre as atrocidades cometidas pelos países do Eixo durante a II Guerra Mundial.

\section{A CONSTRUÇÃO DO REGIME INTERNA- CIONAL DE DIREITOS HUMANOS}

Hoje, ao analisar o papel dos direitos humanos na política internacional contemporânea, vê-se que a divisão entre os que enxergam na sua afirmação internacional uma possibilidade de subverter a lógica de competição entre os estados, que caracteriza o sistema internacional, e aqueles que consideram que a política de direitos humanos é fundamentalmente irrelevante para a condução e para a compreensão dos principais processos políticos internacionais, ainda é muito forte.

Do ponto de vista teórico, a perspectiva da transformação está em grande parte ancorada na percepção, expressa de maneira contundente por Hedley Bull, de que "levado ao seu extremo lógico, a doutrina dos direitos e deveres humanos sob a lei internacional é subversiva de todo o princípio segundo o qual a humanidade deveria ser organizada como uma sociedade de estados" (BULL, 2002, p. 152).

A perspectiva da irrelevância, por sua vez, baseia-se na concepção de cunho realista expressa por autores como Edward Carr (2001) ou Hans Morgenthau (2003), de que a humanidade é uma abstração, e, portanto, a busca da realização dos interesses ou os direitos da humanidade é um exercício inútil. Mais do que isso, dentro da perspectiva realista, quando um ator pretende falar em nome de interesses universais, quase sempre está apenas buscando legitimidade para a defesa de seus

\footnotetext{
${ }^{1}$ Essa última afirmação, sobre a impossibilidade de conhecer os interesses ou os direitos da humanidade como um todo, também serve de base para a formulação de críticas
}

interesses particulares ${ }^{1}$.

O desenvolvimento da política internacional dos direitos humanos ao longo do século XX fornece elementos suficientes para encorajar as duas interpretações. A Declaração Universal dos Direitos Humanos é mais comumente interpretada como uma declaração, que não tem força de lei, pois não tem o formato de um tratado. $\mathrm{O}$ processo de juridiscização dos direitos humanos foi lento e marcado por controvérsias. Até 1951, a ONU trabalhou pela realização de um Pacto Internacional de Direitos Humanos. No entanto, a discordância entre os blocos capitalista e comunista, em torno do significado e da prioridade que deveria ser atribuída à realização dos diferentes grupos de direitos humanos, fez com que a idéia de uma única convenção fosse abandonada e, em seu lugar, surgissem duas convenções, uma relativa aos direitos civis e políticos e outra relativa aos direitos econômicos, culturais e sociais. Da perspectiva do bloco liderado pelos Estados Unidos, os direitos civis e políticos eram passíveis de aplicação imediata, enquanto que os direitos econômicos, culturais e sociais deveriam orientar a elaboração de políticas estatais, mas eram fundamentalmente programáticos. A perspectiva do bloco soviético era exatamente a oposta.

Os dois pactos são finalmente redigidos em 1954, mas são aprovados pela Assembléia Geral somente em 1966, e conseguem o número mínimo de assinaturas para entrar em vigor apenas em 1976. Junto com a Declaração de 1948, eles formam a chamada Carta Internacional de Direitos Humanos. Ao longo dos anos, uma série de outros acordos sobre conjuntos mais específicos de direitos vieram a somar-se a esses documentos iniciais, como por exemplo, a Convenção Contra a Tortura e Outros Tratamentos e Penas Cruéis, Desumanas ou Degradantes (1987); a Convenção Relativa ao Estatuto dos Refugiados (1951); a Convenção Relativa aos Apátridas (1954 e 1961); a Convenção sobre a Eliminação de Todas as Formas de Discriminação da Mulher (1979); a Convenção de Direitos da Criança (1989); a Convenção sobre a Eliminação de Todas as Formas de Discriminação Racial (1965), entre outros. Além

culturais à política internacional dos direitos humanos, interpretada como sendo fundamentalmente um sintoma da dominação cultural do Ocidente sobre o resto do mundo. 
disso, na segunda metade do século XX também foram criados mecanismos regionais, como a Convenção Européia dos Direitos Humanos, a Convenção Africana dos Direitos Humanos (1981) e a Convenção Americana dos Direitos Humanos (1969).

Entre 1947 e 1966, considera-se que a ONU esteve em sua fase abstencionista, preocupada com a redação de normas e a promoção de valores. De 1967 em diante, passou a atuar na fiscalização e em iniciativas para a proteção dos direitos humanos, por meio de investigações promovidas pela Comissão dos Direitos Humanos e também através da atuação dos diversos comitês específicos estabelecidos pelos diferentes Pactos internacionais. A atuação da ONU foi considerada relevante para o fim do regime do apartheid da África do Sul, para as investigações sobre desaparecidos políticos na América Latina, entre outros. Contudo, apesar de alguns casos bem-sucedidos, do ponto de vista de sua efetividade, os pactos e as convenções internacionais relativos aos direitos humanos são considerados como componentes de um regime de soft law, com poucos mecanismos efetivos de execução. Mesmo no caso da condenação de um Estado, ele sofre no máximo um "constrangimento político e moral", a menos que a Assembléia Geral da ONU decida acionar o Conselho de Segurança (situação que será discutida em detalhes mais adiante), o que não acontece com muita freqüência. Dessa forma, a eficácia da política internacional de direitos humanos é bastante questionada. Sobretudo por aqueles que se fixam na ausência de mecanismos internacionais fortes de controle da atuação dos estados no campo dos direitos humanos, e no fato de que o direito internacional dos direitos humanos tem caráter secundário ou subsidiário, ficando a cargo dos estados a responsabilidade primária ou principal por sua execução.

De outro lado, temos alguns autores que consideram que, mesmo com todas as suas limitações, o regime internacional de direitos humanos foi extremamente bem-sucedido no sentido de estabelecer normas - parâmetros internacionais de comportamento - que permitem que a atuação dos estados seja avaliada e julgada. Flávia Piovesan (1997), por exemplo, considera que a Declaração dos Direitos Universais do Homem é parte integrante do Direito Costumeiro Internacional e, dessa forma, pode ser utilizado como um instrumento para avaliar o comportamento de qualquer Es- tado em relação aos direitos humanos.

Mais do que isso, o reconhecimento do indivíduo como portador de direitos que independem dos estados é considerado a mola propulsora da articulação de uma rede transnacional de indivíduos, movimentos sociais e organizações nãogovernamentais, em torno de questões de interesse global.

Essa rede transnacional teve uma atuação importante nos processos de democratização por que passaram diversos países da América Latina e da Europa do Leste em meados da década de 1980. Tem uma participação importante, também, na discussão pública e na busca de soluções para problemas ambientais, e destaca-se, ainda, na tentativa de criar sensibilidade e apoio internacional para a solução de crises humanitárias em diversos lugares do planeta.

O desenvolvimento da rede é interpretado por alguns como o embrião de uma sociedade civil ou de uma esfera pública global que alteraria profundamente a dinâmica da política mundial e tornaria o sistema internacional muito mais próximo do ideal kantiano da paz perpétua. O sistema internacional de direitos humanos teria aqui um papel fundamental, fornecendo legitimidade e estrutura a esse processo. Como sintetiza Gelson Fonseca Júnior (2004, p. 164): "Transforma-se a base social do que é internacionalmente legítimo, já que em muitos temas, a referência é a valores universais. Não são somente os estados que, a partir do interesse, dizem o que é legítimo. Uma outra instância aparece, corre paralela e teria como base a sociedade civil internacional".

É nesse sentido que Bobbio afirma que os direitos positivos universais representam "os direitos do cidadão daquela cidade que não tem fronteiras, porque compreende toda a humanidade, ou em outras palavras, [...] os direitos do homem enquanto cidadão do mundo" (BOBBIO, 1992, p. 30). É também nesse sentido que alguns autores consideram o sistema internacional de direitos humanos como uma espécie de Direito Constitucional Internacional (PIOVESAN, 1997; COMPARATO, 2001).

A expansão do regime internacional de direitos humanos, somada a atuação da rede transnacional de ativistas, contribuiu para que a temática dos direitos humanos alcançasse um amplo grau de consenso perante a sociedade internacional, a ponto 
de converter-se no que Jack Donnely (1998) considera uma "idéia política hegemônica na sociedade internacional do século XX". Isso não significa, é claro, que todos os governos se tenham comprometido igualmente e de fato com a garantia dos direitos humanos, mas apenas que a idéia de que existem direitos humanos inalienáveis e de que "a legitimidade de um governo é baseada na extensão do respeito e defesa aos direitos humanos dos seus cidadãos" torna-se dominante no sistema internacional. A grande questão aqui é saber quais são os efeitos desse processo sobre os processos políticos internacionais ou, posto de outra forma, saber se o reconhecimento internacional de direitos humanos alterou de alguma maneira significativa o panorama político internacional.

Antes de seguirmos adiante com essa indagação, é preciso também destacar que esse processo não pode ser compreendido sem levarmos em consideração os efeitos do fim da Guerra Fria e a construção, pela primeira vez em muitos anos, de uma ordem política internacional homogênea, isto é, onde os conflitos em relação aos critérios de legitimidade política não existem mais. Na década de 1990, essa homogeneidade alimentou a expectativa de que as questões de segurança passariam para o segundo plano da agenda política internacional e de que o mundo enfim poderia dedicarse, por meio de organizações multilaterais como a própria $\mathrm{ONU}$, à solução de graves problemas sociais que afetavam a humanidade. Essa esperança manifestou-se na organização de grandes conferências internacionais a respeito de temas sociais sob os auspícios das Nações Unidas.

\section{DESENVOLVIMENTOS RECENTES}

Uma dessas grandes conferências, diz respeito justamente à questão dos direitos humanos. Em 1993, em Viena, os 171 países membros da ONU reuniram-se para discutir a questão e elaborar uma Convenção Internacional sobre o tema. Além disso, um total de 813 organizações não-governamentais (ONGs) participaram como observadoras e outras 2 mil organizaram um fórum paralelo.

$\mathrm{Na}$ Conferência de Viena, novos temas foram abordados e novos direitos foram reconhecidos; foi criado o Alto Comissariado dos Direitos Humanos com a finalidade de articular as ações das diversas agências da ONU que lidavam com o tema; e por fim, foi sugerido o prosseguimento das discussões sobre a possibilidade de instaura- ção de um Tribunal Penal Internacional para julgar crimes contra os direitos humanos, idéia que se concretiza em 1998, com a assinatura do Tratado de Roma ${ }^{2}$.

No entanto, de acordo com Lindgren Alves, o principal mérito dessa conferência deve-se, sobretudo, à sua representatividade, que "conferiu abrangência inédita aos direitos humanos, ao reafirmar, por consenso, sua universalidade, indivisibilidade, interdependência e inter-relacionamento. Superou assim, resistências derivadas do conflito de civilizações, aceitando a unidade do gênero humano no pluralismo das particularidades das nações e das regiões, e de seus antecedentes históricos, culturais e religiosos. [...] Aceitou, e esse é um ponto-chave, os direitos humanos como tema global e, portanto, como ingrediente de governabilidade do sistema mundial, ao reconhecer a legitimidade da preocupação internacional com a sua promoção e proteção" (ALVES, 2003, p. XXXIII).

$\mathrm{O}$ estabelecimento do consenso internacional em torno da questão leva o debate sobre o papel transformador versus a irrelevância dos direitos humanos para um outro nível; principalmente, porque em função da combinação deste consenso com as mudanças no panorama político internacional, a possibilidade de dotar o sistema internacional de proteção aos direitos humanos de mecanismos coercitivos mais fortes na promoção de uma política mais ativa de garantia dos direitos humanos, passa a ser discutida em termos mais concretos.

Entre o fim dos anos 1980 e início dos anos 1990, havia uma percepção bastante difundida de que "o maior perigo enfrentado pela maior parte das pessoas no mundo atual provém de seus próprios estados, e que o principal dilema da política internacional é saber se as pessoas em perigo devem ser resgatadas pelas forças militares de fora"

\footnotetext{
2 O Tribunal tem como finalidade lidar com os crimes contra a humanidade, de genocídio, crimes de guerra e crime de agressão. Seu funcionamento se baseia no princípio da responsabilidade penal de indivíduos pela prática de delitos contra o Direito Internacional. Apesar da oposição de alguns países, e especialmente da oposição norte-americana, o tratado conseguiu o número mínimo de assinaturas e o Tribunal começou a funcionar em 2002, mas ainda é muito cedo para avaliar seus efeitos sobre a política internacional.
} 
(WALZER, 2003, p. XV).

A dissolução da ex-Iugoslávia e as inúmeras guerras que ela gerou, e a proliferação de conflitos envolvendo violações de direitos humanos em larga escala na África subsaariana alimentaram e ainda alimentam uma extensa discussão sobre a relação entre direitos humanos e soberania. De um lado, existe a idéia de que a soberania de um Estado deve estar condicionada à capacidade de proteger e promover os direitos civis e políticos fundamentais dos cidadãos. De outro, a de que a soberania deve ser inviolável e a busca de soluções para os problemas de direitos humanos deve excluir o uso da força por parte de agentes externos. Neste caso, argumenta-se que a possibilidade de interferência pode minar o respeito e a confiança entre os países (que se sustentam sobre as premissas do sistema vestfaliano), e nesse sentido, tornar a política internacional ainda mais instável.

A lógica subversiva dos direitos humanos à que se referia Hedley Bull parece tornar-se mais evidente no contexto da discussão sobre a legitimidade das intervenções humanitárias. No entanto, a complexidade das relações internacionais contemporâneas faz com que as posições em relação à adequação de tal mecanismo sejam objetos de controvérsia mesmo entre os defensores do regime internacional de direitos humanos. De fato, existe ainda pouca clareza em relação aos possíveis efeitos da interação entre a lógica horizontal dos direitos humanos em um sistema internacional tão fortemente vertical, marcado por imensas assimetrias de poder.

Assim, a década de 1990 caracterizar-se-ia, segundo Andrei Koerner, por um duplo processo: de um lado, existe um avanço no reconhecimento e na proteção dos direitos humanos e, "por outro lado, a situação política internacional mostra como estas relações estão ainda indefinidas, dada a proteção internacional seletiva dos direitos humanos, submetidas aos interesses geopolíticos das principais potências, assim como as reações de suas lideranças e de grupos políticos fundamentalistas, nacionalistas e defensores de outros particularismos, que contestam mudanças mais profundas no campo dos Direitos humanos" (KOERNER, 2002, p. 89).

Duas situações recentes em que a retórica do direito (dever) de intervenção foi levantada são bastante ilustrativas dos problemas envolvendo a questão. Em 1998, a Organização do Tratado do Atlântico Norte (OTAN) bombardeia a Sérvia com o objetivo de pôr fim à guerra do Cosovo e acabar com o massacre de civis. De acordo com um dos arquitetos da intervenção, o primeiro-ministro da Inglaterra, a operação justifica-se não apenas em virtude do imperativo moral, como também pelo fato de que, diante da interdependência que caracteriza o mundo contemporâneo, "nós não podemos dar as costas aos conflitos e violações de direitos humanos dentro de outros países se nós queremos estar seguros". Assim, "a instabilidade financeira na Ásia destrói empregos em Chicago e na minha própria cidade. A pobreza no Caribe significa mais drogas nas ruas de Washington e Londres. Conflitos nos Bálcãs causam mais refugiados na Alemanha e aqui nos Estados Unidos" (BLAIR, 1999). Nunca é demais ressaltar a escolha de regiões e a forma como elas se relacionam em sua fala.

Para o embaixador Lindgren Alves, no entanto, "a verdade é que, em nome dos direitos humanos, com toda a sua tecnologia de ponta, em bombardeios designados cirúrgicos, feitos a partir de vôos de grandes altitude, a OTAN venceu essa guerra não contra os militares sérvios, seguidores até constitucionais do presidente da República, nem contra paramilitares fanáticos, quase sempre os mais cruéis no tratamento de insurretos e simples habitantes pacíficos de outra nacionalidade. Venceu-a sem qualquer baixa, destruindo alvos econômicos de um país inteiro, matando inocentes sérvios, croatas e até mesmo albaneses, destroçando em suas cirurgias não guarnições militares, mas sobretudo instalações civis" (ALVES, 2003, p. XXI).

Como era de esperar, a idéia da legitimidade da intervenção humanitária teve uma recepção um tanto tímida, a não ser entre os intelectuais cosmopolitas. Os países do Sul manifestaram a preocupação de que a nova doutrina representasse mais uma justificativa para a intervenção dos países do centro na periferia, e os do Norte receberam com cautela a idéia da obrigação de ter uma maior participação em conflitos internacionais, onde os interesses envolvidos são pouco claros, em virtude dos custos e dos desgastes envolvidos nesse tipo de operação.

Em 2003, a questão da violação dos direitos humanos volta a ser utilizada como motivo para 
justificar a invasão do Iraque, especialmente depois que não foram encontradas as armas de destruição em massa que supostamente estariam sendo desenvolvidas e armazenadas pelo governo iraquiano. Contudo, embora quase ninguém duvide de que o regime iraquiano desrespeitasse sistematicamente os direitos humanos de seus próprios cidadãos, existem muitas dúvidas sobre por que intervir no Iraque, e não em qualquer outro dos inúmeros estados que violam sistematicamente os direitos humanos de seus próprios cidadãos. Além disso, e igualmente relevante, está longe de ser resolvida a questão da legitimidade dos Estados Unidos e da coalizão por ele liderada, para decidir e levar adiante a intervenção em questão, mesmo para o caso de haver suficientemente evidências de uma tragédia humanitária.

Pesa sobre as intervenções ditas humanitárias a desconfiança de que são decididas não em função de razões humanitárias ou, ao menos, não principalmente em função delas. A imobilidade da comunidade internacional diante do genocídio de 800 mil pessoas em Ruanda, para nos determos apenas no caso mais extremo, parece confirmar estas suspeitas. No entanto, é justamente em função da gravidade de situações como a de Ruanda, que a reflexão sobre as intervenções e sua legitimidade torna-se mais importante. Diante de situações como essa, a questão da representatividade, da estrutura de organização e dos processos decisórios que levam às intervenções adquirem cada vez mais centralidade na análise da política internacional dos direitos humanos.

No âmbito das Nações Unidas, como já dissemos anteriormente, de acordo com o artigo 34 da Carta da ONU, o Conselho de Segurança tem o poder de "investigar qualquer situação ou disputa que possa levar a um confronto ou dar início a uma disputa internacional, com o intuito de determinar se a continuidade da situação ou da disputa pode pôr em perigo a manutenção da paz e da segurança internacional".

Se um caso de violação de direitos humanos for considerado uma possível ameaça à paz e à segurança internacionais, o Conselho pode decidir por uma série de medidas de coerção, como a imposição de embargos comerciais, autorização do uso da força e, em alguns casos, a criação de um tribunal penal internacional. A decisão final é sempre do Conselho. Como bem resume André Ramos (1999, p. 299), “O cerne da questão está em poder o Conselho de Segurança determinar quais violações dos direitos humanos constituem ameaça a paz mundial. Como conseqüência dessa margem de apreciação discricionária do Conselho de Segurança da ONU surge a possibilidade de um novo tipo de responsabilização internacional do Estado por violação de direitos humanos a ser iniciado e processado perante o Conselho de Segurança, sendo a decisão final do procedimento vinculante".

O Conselho de Segurança é formado pelas cinco principais potências mundiais, que são membros permanentes com poder de veto, e por doze membros rotativos. Durante toda a Guerra Fria, as divisões que separavam os membros do Conselho e o uso constante do poder de veto tornaram-no um organismo pouco atuante. No entanto, no contexto atual, ele passou a ter um papel muito mais ativo na política internacional. Talvez por essa razão, a questão da representatividade do Conselho venha sendo cada vez mais debatida. Os críticos consideram que regiões inteiras, como a América Latina e a África, não são devidamente representadas; e que grandes financiadores das operações da ONU, como o Japão e a Alemanha, que também não são membros, deveriam ser.

Além disso, destaca-se também o fato de que não existe nenhum controle de legalidade sobre as decisões dos países membros. O tratamento dado a questões envolvendo os direitos humanos no Conselho, por exemplo, é muito desigual, de modo que não se pode estabelecer um padrão nas condenações estabelecidas por ele. Dessa forma, a estrutura de proteção internacional aos direitos humanos do ponto de vista democrático é um fiasco. Como argumenta Robert Dahl (1982, p. 15), "por mais deficiente que a poliarquia seja em preencher os critérios do processo democrático, nenhuma organização internacional, pelo menos nenhuma com um poder significativo de tomar decisões, nem remotamente se aproxima da poliarquia no preenchimento desses critérios. A maior parte destas organizações são, na melhor das hipóteses, meritocracias exercendo um poder delegado por instituições políticas dos países membros".

A discussão sobre a legitimidade das intervenções não pode ser feita separadamente de uma reflexão sobre a estrutura de poder no sistema internacional e a forma como esta estrutura se reflete nos processos decisórios dentro das organizações internacionais, sobretudo da própria 
ONU. Como observa David Held (2005, p. 12), "as correias de transmissão de estados nacionais para os organismos multilaterais de produção de regras são muito longas, as bases de representação são pouco claras, e os mecanismos de accountability das elites técnicas que dirigem as organizações internacionais é fraco ou obscuro. Problemas de transparência, accountability e democracia prevalecem no nível global". Isso é tão mais problemático na medida em que, no final do século XX, a democracia também adquire o status de uma idéia política hegemônica no sistema internacional. De modo que a discrepância entre a forma como as decisões são tomadas no interior da ONU e os critérios democráticos mínimos reflete-se num crescente déficit de legitimidade da organização.

Para David Held, o conceito de democracia só pode ser redimido na esfera transnacional através da construção de uma democracia cosmopolita que buscaria "firmar e desenvolver instituições políticas regionais e globais como um complemento necessário ao Estado-Nação". Seria um sistema onde o Estado nacional coexistiria com instituições transnacionais que decidiriam sobre assuntos "com conseqüências transnacionais e internacionais comprovadas que requeiram iniciativas globais ou regionais no interesse de sua efetivação e que dependam dessas iniciativas para a manutenção de sua legitimidade democrática" (HELD, 1991, p. 24). Ele propõe uma série de medidas em direção a essa democracia cosmopolita que culminam com a formação de um parlamento global, que conecte regiões, nações e localidades. Os críticos de Held consideram suas propostas muito distantes da realidade do sistema internacional para serem consideradas uma alternativa viável (CRUZ, 2002).

Outros, para lidar com a questão do déficit democrático, apostam no desenvolvimento da chamada sociedade civil global. De acordo com esse argumento - embora as entidades que agora detêm poder efetivo, que criam leis e impõem regras não sejam nem internamente democráticas, nem transparentes ou responsabilizáveis - a emergência desse novo ator pode ajudar a tornar públicas as grandes questões e democratizar a ordem mundial emergente. Como observa Jean Cohen, "esses teóricos acreditam que uma sociedade civil em escala global poderia compensar o déficit democrático da nova ordem mundial " (COHEN, 2003, p. 421).
Para autores como Mary Kaldor, a emergência da rede internacional de movimentos sociais alterou significativamente o panorama das relações internacionais. Hoje, "a crescente interconexão entre os estados, a emergência de um sistema de governança global, e a explosão de movimentos, grupos, redes e organizações engajadas em um debate público global ou transnacional, colocaram em questão a primazia dos estados" (KALDOR, 2003, p. 583). Embora o Estado continue a existir e a ser o depositário da soberania, esta se torna muito mais condicional do que antes, dependendo do consentimento interno e do respeito externo. O sistema internacional é, cada vez mais, composto de outras instituições políticas, indivíduos, grupos, instituições internacionais e empresas.

As ONGs em especial, são consideradas os atores mais relevantes da sociedade civil em construção. Ao longo dos últimos anos, elas multiplicaram-se, estenderam-se pelo mundo formando redes com estruturas internacionais e foram ficando cada vez mais legitimadas pela estrutura formal de proteção aos direitos humanos. Estabeleceram uma parceria estável com a ONU e são consideradas como as representantes da opinião pública global. Elas podem tecer comentários sobre relatórios enviados pelos países, que farão parte do material encaminhado ao Conselho Econômico e Social e à Assembléia Geral da ONU, e algumas delas têm estatuto consultivo. Isso significa que elas podem enviar informes ao Conselho e participar da elaboração das convenções internacionais (KECK \& SIKKINK, 1998; BEETHAM, 1999; RAMOS, 1999; ALVES, 2003).

Para ter-se uma idéia da evolução da participação das ONGs, em 1973, na Conferência de Direitos Humanos de Teerã, tinham status consultivo 53 ONGs e quatro participaram do comitê preparatório. Em Viena, em 1993, havia 248 ONGs com status consultivo e 593 participantes. Além disso, estima-se que entre 1,4 mil a 1,5 mil ONGs participaram do evento paralelo (CLARK, FRIEDMAN \& HOCHSTETLER, 1998).

As ONGs não apenas representam a possibilidade de participação política do indivíduo em nível global, como também, de acordo com alguns autores como Margareth Keck e Kathryn Sikkink, têm um efeito positivo de aprofundamento da democracia dentro do Estado, como é sugerido nessa passagem: "Ao construir novos laços entre os ato- 
res nas sociedades civis, estados e organizações internacionais, elas multiplicam os canais de acesso ao sistema internacional. Em áreas chaves como meio ambiente e direitos humanos, elas também tornam os recursos internacionais disponíveis a novos atores da política doméstica e das lutas sociais. Dessa forma obscurecendo as fronteiras entre a relação do Estado com seus próprios cidadãos e o acesso que tanto os estados como os cidadãos têm ao sistema internacional, as redes de advocacia estão ajudando a transformar a prática da soberania nacional" (KECK \& SIKKINK, 1998, p. 2).

Outros autores, como a própria Kaldor (2003), reconhecem que, embora as redes internacionais ofereçam um potencial de emancipação para os indivíduos, aumentando a possibilidade de participação e influência em assuntos globais, elas não são democráticas nem igualitárias, além de serem dominadas pelos países do Norte.

De modo geral, ainda se sabe muito pouco sobre a forma como se dá essa interação entre as ONGs e as organizações internacionais. Também faltam estudos sobre o funcionamento interno dessas organizações, a forma como elas são estruturadas, como são escolhidas as suas campanhas e quem financia suas atividades. Além disso, os interesses dos estados permanecem muito poderosos nas organizações internacionais. Como observam Clark, Friedman e Hochstetler (1998, p. 6), mesmo na preparação das conferências internacionais, "os estados continuam a dominar os procedimentos e o conteúdo da interação nas questões chaves relacionadas à soberania".

Por fim, de acordo com o argumento de Jean Cohen, a confiança na capacidade da sociedade civil global em democratizar o sistema internacional, superestima a capacidade de ação desse ator, e subestima a sua própria necessidade de ser democratizado. Em suas palavras: "é um erro considerar que as organizações não-governamentais, associações locais e redes que povoam a sociedade civil transnacional como equivalentes funcionais das instituições representativas e da sociedade política (partidos, sindicatos) na esfera nacional em democracias constitucionais. A sociedade civil não consegue fiscalizar por conta própria as novas e poderosas instituições supranacionais ou subnacionais de governança. A verdade é que a própria sociedade civil precisa ser fiscalizada. Redes e associações civis podem ser muito excludentes, injustas, desiguais e antidemocráticas" (COHEN, 2003, p. 450).

\section{CONCLUSÃO}

Em resumo, é importante destacar que a crescente exigência de que os estados sejam democráticos para serem considerados legítimos no sistema internacional contrasta fortemente com o baixo grau de democratização das instituições internacionais, que cada vez mais afetam a vida e as possibilidades dos indivíduos no mundo, hoje. Essa discrepância afeta a própria forma como a ordem internacional é percebida, e faz com que as tentativas de estabelecer uma política mais efetiva de garantia dos direitos humanos, sejam vistas, não sem razão, com uma boa dose de ceticismo. Além disso, a crescente incorporação da retórica dos direitos humanos na formulação dos objetivos de política externa de atores importantes do sistema internacional, como os Estados Unidos e a GrãBretanha, acaba tendo um efeito contraproducente, do ponto de vista de uma política internacional de direitos humanos. A dificuldade em distinguir os interesses particulares dos imperativos morais em ações como o bombardeio da Sérvia ou a invasão do Iraque contribuem para criar uma atmosfera de desconfiança em relação à política dos direitos humanos. Isso se tem refletido até mesmo em uma postura hostil às ONGs que trabalham com direitos humanos e direitos humanitários nas zonas atingidas por conflitos violentos.

De fato, podemos afirmar que a retórica dos direitos humanos tornou-se tão forte que as mais diversas propostas políticas tentam de alguma forma expressar sua proposta em uma linguagem compatível com os direitos humanos. Isto nos remete ao nosso problema inicial, sobre a formação do regime internacional de proteção aos direitos humanos, e sobre o significado da construção desse regime para as relações internacionais. A variedade de propostas que se escondem sob o manto da retórica dos direitos humanos é tão ampla, que torna mais do que nunca necessária uma reflexão sobre a política internacional dos direitos humanos.

Isso é tanto mais importante se considerarmos que nós vivemos em um sistema internacional profundamente assimétrico em termos de distribuição de poder, e que o processo de globalização econômica vem contribuindo para a intensificação dessas diferenças. Como observa Gelson Fonseca Júnior (2004, p. 164), “a própria 
persistência da desigualdade social e das diferenças culturais, além naturalmente das modalidades de inserção geopolítica, constituem a base de processos conflitivos que perdurarão e se projetarão necessariamente no debate sobre o que é legítimo".

Uma vez superada a dicotomia Leste-Oeste, a atenção volta-se para a relação Norte-Sul, centroperiferia. Dentro desta relação, a compreensão do papel do regime internacional de proteção aos direitos humanos é particularmente importante. Ele pode ser interpretado tanto como uma ferramenta para a construção de uma sociedade mundial mais justa, quanto como um instrumento que legitima e justifica as assimetrias do sistema internacional, separando civilização e barbárie, como pode ser visto em sugestões como a do "imperialismo pósmoderno", do diplomata de carreira inglês Robert Cooper, em artigo para o jornal The Guardian: "O mundo pós-moderno tem que começar a se habituar com padrões duplos. Entre nós, nós operamos na base de leis e segurança cooperativa. Mas ao lidar com estados old-fashioned fora do pósmoderno continente da Europa, nós temos que retornar aos métodos rudes de uma antiga era força, ataques preventivos, sabotagens, o que for necessário para lidar com aqueles que ainda vivem no mundo do século XIX, de cada um por si. [...] O que é necessário é uma nova forma de imperialismo, uma que seja compatível com direitos humanos e valores cosmopolitas: um imperialismo cujo objetivo seja trazer ordem e organização, mas que se apóie hoje sobre o princípio da voluntariedade" (COOPER, 2002).

Os países mais fracos do sistema encaram com preocupação genuína a adoção de uma política mais ativa de proteção aos diretos humanos em termos internacionais. A grande dificuldade aqui é que as ameaças aos direitos humanos persistem e são graves. No entanto, a questão sobre a viabilidade e mesmo a adequação de uma política internacional de direitos humanos dotada de mecanismos coercitivos mais fortes que os atuais, considerando-se a estrutura profundamente assimétrica das relações internacionais, exige a retomada da tradicional e infindável reflexão sobre a relação entre poder e moral nas relações internacionais que parece, mais do que nunca, extremamente atual.

Rossana Rocha Reis (rossanarr@uol.com.br) é Professora do Departamento de Ciência Política da Universidade de São Paulo (USP) e pesquisadora do Núcleo de Apoio aos Estudos de Democratização e Desenvolvimento da mesma universidade (NADD-USP).

\section{REFERÊNCIAS BIBLIOGRÁFICAS}

ALVES, J. A. L. 2003. Os direitos humanos como tema global. São Paulo : Perspectiva.

ARON, R. 1986. Paz e guerra entre as nações. Brasília: UNB.

BEETHAM, D. 1999. Democracy and Human Rights. Cambridge : Polity.

BLAIR, T. 1999. Doctrine of International Community. Speech by the Prime Minister, Tony Blair, to the Economic Club of Chicago, April 22 1999. Disponível em : http:// www.fco.gov.uk/servlet/front? pagename $=$ openmarket/xcelerate/ showpage $\& \mathrm{c}=$ page $\&$ cid $=1007029391647 \& \mathrm{a}=$ karticle\&aid $=1013618397478 \% 20 \& y e a r=$ 1999\&month=1999-04-01\&date=1999-04-23 . Acesso em : 15.dez.2006.
BOBBIO, N. 1992. A era dos direitos. Rio de Janeiro : Campus.

BULL, H. 2002. A sociedade anárquica. São Paulo : Instituto de Pesquisa de Relações Internacionais.

CARR, E. 2001. Vinte anos de crise : 1919-1939. São Paulo : Instituto de Pesquisa de Relações Internacionais.

CLARK，A. M.; FRIEDMAN，E. J. \& HOCHSTETLER, K. 1998. The Sovereign Limits of Global Civil Society. A Comparison of NGO Participation in UN World Conferences on the Environment, Human Rights and Women. World Politics, Baltimore, n. 51, n. 1, p. 1-35, Oct. 
COHEN, J. 2003. Sociedade civil e globalização : repensando categorias. Dados, Rio de Janeiro, v. 46, n. 3, p. 419-459.

COMPARATO, F. K. 2001. A afirmação histórica dos direitos humanos. São Paulo : Saraiva.

COOPER, R. 2002. Why We Still Need Empires. The Observer, London, Apr.7. Disponível em : http://observer.guardian.co.uk/comment/story/ 0,,680096,00.html. Acesso em : 15.dez.2006.

DAHL， R. 1982. Dilemmas of Pluralist Democracy : Autonomy vs. Control. New Haven : Yale University.

DONNELY, J. 1998. Direitos humanos, democracia e desenvolvimento. Artigo apresentado no Seminário Direitos Humanos no século XXI, realizado em 10 e 11 de setembro, no Rio de Janeiro. Disponível em : http:// www 2.mre.gov.br/ipri/Papers/ DireitosHumanos/Artigo07.doc. Acesso em : 12.dez.2006

FALK, R. 1994. Conference on Security Council Reform. Princeton : Princeton University.

FONSECA JÚNIOR, G. 2004. A legitimidade e outras questões internacionais : poder e ética entre as nações. Rio de Janeiro : Paz e Terra.

HELD, D. 1991. A democracia, o Estado-nação e o sistema global. Lua Nova, São Paulo, n. 23, mar.

. Globalization, international law and human rights. Disponível em : http:// www.lse.ac.uk/Depts/global/Publications/ PublicLectures/PL_Globalization International LawandHuman Rights.pdf. Acesso em : 15.dez.2006.
KALDOR, M. 2003. The Idea of a Global Civil Society. International Affairs, London, v. 79, n. 3, p. 583-593, May.

KECK, M. \& SIKKINK, K. 1998. Activists beyond Borders : Advocacy Networks in International Politics. New York : Cornell University.

KOERNER, A. 2002. Ordem política e sujeito de direito no debate sobre direitos humanos. Lua Nova, São Paulo, n. 57, p. 87-111.

LAFER, C. 1997. A reconstrução dos direitos humano : a contribuição de Hannah Arendt. Estudos Avançados, São Paulo, v. 11, n. 30, maio-ago.

MORGENTHAU, H. 2003. A politica entre as nações. São Paulo : Instituto de Pesquisa de Relações Internacionais.

PIOVESAN, F. 1997. Direitos humanos e o Direito Constitucional Internacional. $2^{\mathrm{a}}$ ed. São Paulo : M. Limonade.

RAMOS, A. C. 1999. A responsabilidade internacional do Estado por violação de Direitos Humanos. São Paulo. Tese (Doutorado em Direito). Universidade de São Paulo.

CRUZ, S. V. 2002. Democracia e ordem internacional : reflexões a partir de um país grande semiperiférico. Primeira Versão, Campinas, $\mathrm{n}$. 103, p. 1-61, mar.

WALZER, M. M. 2003. Guerras justas e injustas. Uma argumentação moral com exemplos históricos. São Paulo : M. Fontes. 